\title{
BIOLINGUÍSTICA: DA EVOLUÇÃO DA ESPÉCIE À NOÇÃO \\ DE PARÂMETROS
}

\section{BIOLINGÜÍSTICA: DESDE LA EVOLUCIÓN DE LA ESPECIE HASTA LA NOCIÓN DE PARÁMETROS}

BIOLINGUISTICS: FROM SPECIES EVOLUTION TO THE NOTION OF PARAMETERS

\author{
Danniel da Silva Carvalho \\ Fernanda de Oliveira Cerqueira ${ }^{* *}$ \\ Victor Cavalcanti Mariano ${ }^{* * *}$ \\ Universidade Federal da Bahia
}

\begin{abstract}
RESUMO: A Biolinguística pretende lançar luz sobre a natureza eminentemente biológica da linguagem humana, focando, entre outros fatores, (i) as propriedades fenotípicas da língua; (ii) o crescimento e o amadurecimento da capacidade da linguagem nos indivíduos; (iii) a implementação da linguagem no cérebro; e (iv) os processos evolutivos que levaram ao surgimento da linguagem. Estes aspectos fundamentais são usados neste trabalho para enquadrar uma descrição de questões importantes no estudo da linguagem, levando a uma discussão sobre os avanços da linguística teórica, psicolinguística, comportamento animal comparativo, psicologia e genética/genômica, disciplinas que podem agora colocar esses fatores de longa data em uma nova perspectiva, ao levantar desafios para futuras pesquisas.
\end{abstract}

PALAVRAS-CHAVE: Arquitetura da linguagem. Evolução. Faculdade da linguagem. Teoria linguística.

RESUMEN: La biolingüística pretende arrojar luz sobre la naturaleza eminentemente biológica del lenguaje humano, centrándose, entre otros factores, (i) en las propiedades fenotípicas de la lengua, (ii) en el crecimiento y la maduración de la capacidad del lenguaje en los individuos; (iii) en la puesta en práctica del lenguaje en el cerebro; y (iv) en los procesos evolutivos que dieron lugar a la aparición del lenguaje. Estos aspectos clave se utilizan en este trabajo para enmarcar una descripción de los problemas importantes en el estudio del lenguaje, lo que lleva a una discusión de los avances de la lingüística teórica, la psicolingüística, la conducta animal

\footnotetext{
Doutor em Linguística, professor de Linguística do Instituto de Letras e do Programa de Pós-Graduação em Língua e CulturadaUniversidade FederaldaBahia.E-mail: dannielcarvalho@ufba.br. 
comparada, psicología y genética/genómica, disciplinas que ahora pueden poner estos factores de larga trayectoria en una nueva perspectiva, al destacar retos para investigaciones futuras.

PALABRAS-CLAVE: Arquitectura del lenguaje. Evolución. Facultad del lenguaje. Teoría lingüística.

ABSTRACT: Biolinguistics aims to shed light on the eminently biological nature of human language, focusing on, among other factors, (i) the phenotypic properties of language, (ii) the growth and maturation of the capacity of language in individuals; (iii) the implementation of language in the brain; and (iv) the evolutionary processes that led to the emergence of language. These key aspects are used in this work to frame a description of important issues in the study of language, leading to a discussion of advances in theoretical linguistics, psycholinguistics, comparative animal behavior and psychology, genetics/genomics, disciplines that can now put these long-dated factors in a new perspective, to raise challenges for future research.

KEYWORDS: Language architecture. Evolution. Language faculty. Linguistic theory.

\section{CONTEXTUALIZANDO A BIOLINGUÍSTICA}

Em 1974, houve uma conferência internacional no Instituto de Tecnologia de Massachussets - MIT, a qual se intitulou Biolinguística, termo cunhado por Massimo Pittelli-Palmarini. O evento contou com a presença de biólogos evolucionistas, neurocientistas, linguistas e outros profissionais atentos a discussões acerca de língua e biologia. Segundo Chomsky (2007), embora o embrião dessa proposta tenha surgido na década de cinquenta, com os debates sobre a exequibilidade da proposta behaviorista de aquisição da linguagem humana, as discussões referentes à biolinguística iniciaram-se, ainda que de maneira incipiente, por alunos de graduação capazes de identificar a interdisciplinaridade entre as áreas de matemática, biologia e linguística. Assim, após o amadurecimento de tais debates, um destes alunos, Eric Lenneberg, publicou, em 1967, um livro de grande relevância para o campo em questão, a saber, Biological Foundations of Language.

Sabe-se que, na década de 1950, a Linguística estava sob forte influência da perspectiva comportamentalista. Autores como John Broadus Watson, Ivan Pavlov e, sobretudo, Burrhus Frederic Skinner corroboraram com a abordagem psicológica, baseada na concepção de que organismos vivos possuem seus padrões de comportamento orientados por estímulos externos reforçados positiva ou negativamente por suas respostas. Deste modo, os behavioristas descartam a existência de qualquer comportamento do indivíduo condicionado internamente, visto que uma das bases da proposta é o modelo da tábula rasa, cuja assunção implica em conceber que não há, nos organismos vivos, nenhum tipo de capacidade decorrente de sua fisiologia. Logo, todas as suas habilidades seriam provenientes de experiências externas motivadas por estímulo-resposta-reforço.

Tradicionalmente, assume-se que os trabalhos de Watson e Pavlov registram e orientam a primeira fase do behaviorismo, o behaviorismo metodológico. Entretanto, são os trabalhos de Skinner que demonstram especial interesse em definir uma metodologia pertinente à proposta. Embora Skinner seja referência para a segunda fase do behaviorismo, conhecida como behaviorismo radical, suas experiências, diferentemente dos experimentos de primeira fase, foram predominantemente realizadas com animais, em busca de compreender o condicionamento operante dos organismos, a partir da investigação dos operantes livres (comportamentos aleatórios) e dos operantes condicionados (comportamento motivado por estímulo-resposta). À proporção que a metodologia da proposta behaviorista é estabelecida, Skinner passa a demonstrar interesse na linguagem humana, assumindoa, consequentemente, como mais um comportamento do organismo humano, orientado pelos mesmos padrões de qualquer outro comportamento como andar, andar de bicicleta, escrever, cozinhar, pescar, correr, entre outros.

Como resultado de suas reflexões, Skinner publica, em 1957, o livro Verbal Behavior, no qual argumenta que cada ato de fala é decorrente do ambiente do organismo humano e de sua trajetória comportamental. Para Skinner, "[...] aprender a falar, assim como outras formas de comunicação, é um comportamento submetido às mesmas leis dos demais tipos de comportamento humano" (FINGER, 2008, p. 27). Em decorrência do estranhamento a uma proposta na qual se concebe similitude entre o comportamento de eventos espontâneos, como falar, e o comportamento de eventos decorrentes de aprendizagem, como nadar, andar de bicicleta ou escrever, Chomsky inicia um fervoroso debate contestando a teoria behaviorista. 
Em 1959, Chomsky publica a resenha intitulada A review of B.F. Skinner's Verbal Behavior, apontando dois aspectos essenciais para a reconsideração da proposta behaviorista de aquisição da linguagem e, não obstante, para o surgimento da teoria gerativista. Para Chomsky, a exclusão da criatividade e da recursividade linguística impactam muito negativamente na teoria behaviorista, uma vez que em qualquer língua humana surgem novas formas, mas as novas formas surgem de modo a atender ao sistema linguístico. Deste modo, como uma teoria cuja metodologia descarta a criatividade do falante daria conta dos "erros" em aquisição de língua materna, quando a criança produz uma estrutura jamais ouvida antes e, portanto, impossível de ser imitada?

A hipótese do condicionamento operante, oriunda da tríade estímulo-resposta-reforço, mostra-se insuficiente para responder à questão supracitada pelo fato de pressupor que todo conhecimento do falante é proveniente de suas relações com o ambiente externo. Assim, Chomsky postula outra questão de suma importância: como uma criança de até seis anos é capaz de produzir e compreender todas as sentenças de uma língua sem ter sido exposta a todas essas possibilidades? A recursividade, condição de qualquer língua humana dispor de um conjunto finito de possibilidades para formar um conjunto infinito de expressões, não é objeto dessa proposta, assim como a capacidade espontânea da qual falantes nativos dispõem para usufruir desse sistema de regras, a competência, também não é considerada. Identifica-se que o método da tábula rasa é ineficaz para a compreensão da complexidade da língua e, visando responder a essas questões, tem início o empreendimento gerativista.

No que concerne à assunção de língua como sistema homogêneo decorrente de estímulos externos, destaca-se o nome de Bloomfield, cuja produção dialogou intimamente com o aporte teórico estruturalista e com a proposta behaviorista de aquisição da linguagem, diálogo que caracterizou em termos gerais a vertente estruturalista norte-americana. Ainda que a tradição estruturalista norte-americana tenha, em sua maioria, baseando-se na referida hipótese de aquisição, Chomsky (2007) reconhece que a produção estruturalista é basilar para concepção da Linguística como ciência, a partir da definição de um objeto específico de investigação, como também de uma metodologia específica.

Naturalmente, esse reconhecimento decorre de a tradição estruturalista render contribuições especiais ao gerativismo. Ter Harris como orientador, por exemplo, possibilitou a Chomsky debates nos quais se formulou a noção de língua como um sistema de regras finitas inatas aos falantes de uma língua particular, ao passo que se problematizou a assunção de língua como sistema de signos, virtual e instituída socialmente. A produção, na qual se identifica mais claramente uma releitura de concepções estruturalistas, mas que contribuiu substancialmente para uma teoria formal pautada na autonomia da sintaxe, é o livro Estruturas Sintáticas, da autoria de Chomsky, publicado, em 1957, como produto de sua tese.

Em 1965, Chomsky publica o livro Aspecto da teoria sintática, ampliando mais um pouco o escopo do empreendimento gerativista. Entretanto, é na década de 1980, mais especificamente com o lançamento dos livros Regência e Ligação, em 1981, e O conhecimento da língua: sua natureza, origem e uso, em 1986, que há o diálogo mais íntimo com a biologia, intentando solucionar questões como: O que é o conhecimento da língua?; Como esse conhecimento é adquirido?; e Como esse conhecimento é posto em uso? Logo, definir de maneira mais coesa conceitos como faculdade da linguagem, gramática universal, competência e desempenho foi uma demanda atendida na década de 1980. Outra contribuição contemporânea às supracitadas é a noção de princípios e parâmetros.

Em 1995, Chomsky publica o Programa Minimalista, trabalho proveniente de uma grande revisão da proposta teórica e de suas bases, de modo a promover explicações atingindo o nível na adequação explicativa e não só o nível da adequação descritiva, como vinha ocorrendo. Dessa forma, muitos pontos do modelo de Regência e Ligação foram rediscutidos e modificados, tais como: a necessidade de estrutura profunda (reconsiderada dado ao seu custo para a sintaxe), a noção de léxico (não mais visto como item de vocabulário, mas como conjunto de traços formais e interpretáveis), as noções de forma lógica e forma fonética (ampliadas para interfaces de modo a atender a arquitetura da linguagem), a assunção de uma sintaxe capaz de atuar com apenas duas operações (merge e move), entre outras. No entanto, a mudança no escopo de interesse da teoria gerativista, que viabilizou discussões essenciais para uma proposta biolinguística, foi a inserção da questão "Como é que estas propriedades se realizam no mecanismo do cérebro?" (CHOMSKY, 1995, p. 55). Reflexões sobre como a espécie humana passa a dispor de um aparato linguístico plenamente eficaz e econômico são basilares para o amadurecimento da proposta Biolinguística. 
Para Longobardi e Guardiano (2011), a Linguística Comparativa do século XIX forneceu bases para a Biolinguística, pois, segundo os autores, o interesse em agrupar as línguas humanas em famílias, partindo de aproximações em nível fonético/fonológico, em prol da descoberta da primeira língua humana, o protoindo-europeu, teria sido o primeiro ponto de intersecção entre estudos sobre língua e estudos sobre biologia. Contudo, é necessário delinear objetivamente como surgiu a proposta biolinguística e quais são seus interesses.

\section{A PROPOSTA BIOLINGUÍSTICA}

A perspectiva biolinguística argumenta em prol de que a capacidade de produzir e compreender língua seja decorrente da existência de um órgão responsável pela competência linguística, logo, “[...] diz respeito à faculdade da linguagem como 'órgão do corpo’ junto com outros sistemas cognitivos" (CHOMSKY 2005, p. 1). Sendo assim, é objetivo da biolinguística apontar de que modo a faculdade da linguagem desenvolveu-se no homo sapiens e por que a língua é uma particularidade dessa espécie.

A faculdade da linguagem é concebida como um componente do cérebro responsável pela língua na medida em que se articula com outros módulos mentais, como a memória. Assim, essa perspectiva vê a faculdade da linguagem como o sistema de visão dos mamíferos, como o sistema comunicativo dos insetos ou como o sistema digestivo humano, à proporção que é um aspecto da fisiologia da espécie, as condições que promovem "comportamento" linguístico são espontâneas e não motivadas.

Para Chomsky (2005), a adoção dessa proposta implica, necessariamente, em dispor de três fatores para determinação de língua interna (LI), a qual é compreendida como "[...] o conhecimento mental puro de uma língua particular por parte do sujeito falante, isto é, sua gramática interiorizada” (CHOMSKY, 1965 apud RAPOSO, 1992, p. 31). Os três fatores, por sua vez, são: (i) o desenvolvimento genético, como uma premissa para o surgimento de uma Gramática Universal (GU); (ii) a experiência, atribuída ao input linguístico, gatilho para a aquisição de língua materna; e (iii) a noção de princípio equivalendo à língua ou ao organismo independente.

O sustentáculo de uma proposta como a biolinguística está em argumentar em favor de que a competência linguística, a qual parece ser uma particularidade dos humanos, tenha surgido nessa espécie por uma razão particular, isto é, uma virada na evolução da espécie pode ter proporcionado uma mudança genética responsável pelo surgimento de uma GU nos humanos capaz de diferenciar muito significativamente a língua dos sistemas comunicativos dos animais (DI SCIULIO, BOECKX, 2011; CHOMSKY, 2016). Por conseguinte, ao passo que se deu a evolução desse aparato na espécie humana, é preciso considerar como se dá o seu funcionamento e, para tanto, é necessário assumir que os princípios linguísticos, presentes na GU, são parcialmente rígidos, sendo uma parcela deles marcado positiva ou negativamente, conforme acionado pelo input. Considerando que os dados linguísticos primários são degradados em termos de gramática, finitos em termos de amostra e pobres em termos qualitativos (JENKINS, 2011), é lícito postular que uma parcela muito relevante desse conhecimento linguístico é de natureza inata.

\subsection{A PERSPECTIVA EVOLUCIONISTA}

Opondo-se à hipótese criacionista de formação do globo terrestre, o físico George Gamow e o astrônomo Georges Lemaitre propuseram, com base na Teoria da Relatividade (EINSTEIN, 1905; SLIPHER, 1923; HUBBLE, 1929), a hipótese no Big Bang, na qual o surgimento do Planeta Terra, assim como de outros astros, seria oriundo de uma grandiosa explosão, da qual teria resultado o afastamento das galáxias e teria culminado no surgimento do Universo, há aproximadamente treze bilhões de anos. A Terra, por sua vez, teria surgindo há cerca de 4,5 bilhões de anos em decorrência de uma suposta mistura de poeira e gases dissidentes da formação do Sol. Ao logo de bastante tempo, esse componente teria permanecido em estado de fusão e, posteriormente, teria resultado em uma separação de elementos secos e uma porção aquosa, as quais, ao logo de muito tempo, ocasionou em superfícies terrenas e rios e oceanos respectivamente. 
Acredita-se que inicialmente essa superfície terrena tenha se originado como uma espécie de "supercontinente" chamado de Rodínia, depois de Panótia e, por fim, de Pangeia. Sendo assim, conforme a escala de tempo geológico, no período Hadeano, a Terra estava superaquecida em função de rochas em ebulição, de vulcões ativos e explosão de asteroides; no período Arqueano, houve perda de calor e resfriamento, culminando, ao longo de milhares de anos, em chuvas e na formação do oceano; no período Proterozóico, teriam surgido os primeiros organismos vivos do planeta; e na era Fanerozóica, teria ocorrido a redução mais significativa das atividades vulcânicas e o surgimento de espécies marinhas e terrestres no planeta, a formação e a divisão do supercontinente e a divisão do continente até sua formação atual, promovendo a formação de novas cadeias de montanhas, de novos ecossistemas e do surgimento do homo sapiens. A hipótese mais forte acerca do desenvolvimento da vida na terra é a da evolução das espécies.

Para muitos arqueólogos, a espécie humana teria surgido na África e migrado para outros espaços, após o movimento das placas tectônicas promoverem a separação dos continentes. Tattersall (1998) demonstra embriões de um desenvolvimento social no continente africano que serviria para muitos arqueólogos como argumento para o ponto de vista supracitado, o que parece evidenciar que, nesse momento, os humanos já dispunham de um sistema comunicativo mais ou menos elaborado. Logo, a faculdade da linguagem deve ter se desenvolvido ao logo desse período,

[...] [a] faculdade da linguagem é um componente cujo fator de confusão de uma teoria evolutiva moderna Alfred Russel Wallace chamou de "natureza intelectual e moral do homem": a capacidade humana de criatividade para imaginação, linguagem, e sistemas gerais como matemática, interpretação e recordação de um fenômeno natural intricado a práticas sociais semelhantes a um complexo de capacidades que parece ter sido cristalizada recentemente, talvez um pouco mais que 50.000 anos atrás entre a pequena reprodução de um grupo do qual todos nós somos descendentes (CHOMSKY, 2005, p. 03).

Para Wallace, autor contemporâneo a Darwin $^{1}$, a seleção natural, como proposta, seria insuficiente para justificar o desaparecimento de algumas espécies e a perpetuação das mais adaptadas no decorrer da história do globo terrestre. Para ele, haveria algo intrínseco à espécie adaptada para que ela desenvolvesse as habilidades necessárias para sobrevivência às condições ambientais. Muitos anos após a discussão entre Darwin e Wallace, Mendel desvenda o que seria essa "motivação intrínseca", chamada por Wallace e Sutton de genética.

Argumenta-se, nesse sentido, que a capacidade intelectual humana está intimamente relacionada à faculdade da linguagem, e, se a primeira evoluiu nas espécies como produto de uma dotação genética, é plausível assumir que a faculdade da linguagem tenha evoluído nos mesmos moldes. Para que todos os indivíduos de uma mesma espécie tenham sofrido a mesma mutação, que lhes tenha proporcionado desenvolver um aspecto adaptável, é preciso assumir que esse processo tenha se dado a partir de dotação genética (FEDOR et al., 2009).

Segundo Chomsky $(2005,2007)$, Jared Diamond compreende que essa capacidade humana, desenvolvida evolutivamente, seja resultado de alguns eventos genéticos, os quais, relacionados ao cérebro, possibilitam a origem de uma língua natural com sintaxe complexa, promovendo uma vasta gama de expressões de pensamento. No entanto, autores como Gallistel (1990) e Stemmer (1999) defendem que a arquitetura da mente é modular e que elementos desse módulo mental responsáveis pela cognição estariam presentes na mente dos animais.

Nas palavras de Gallistel, em todos os animais, a aprendizagem é baseada em "mecanismos de aprendizagem" especializados, "institutos para aprender" em caminhos específicos, estes são essencialmente "órgãos dentro do cérebro que são circuitos neurais" cuja estrutura lhes permite efetuar um determinado tipo de computação, como eles fazem mais ou menos reflexivamente em ambientes extremamente hostis (STEMMER, 1999, p. 394).

\footnotetext{
${ }^{1}$ Sabe-se que, apesar da discordância quanto à existência e à disposição dessa predisposição intrínseca ao indivíduo para a seleção natural, Darwin e Wallace concordaram em muitos aspectos, sobretudo em reinterpretar a Lei da Pressão Populacional, proposta por Malthus, em 1798, como argumento contra a hipótese evolucionista de Lamarck cuja condição adaptada da espécie não extinta era obtida em função de um esforço.
} 
Gallistel defende que a aprendizagem e o instinto animal sejam fortes indicativos de que eles dispõem de cognição. Sendo assim, se os animais possuem cognição, é lícito afirmar que também dispõem de um sistema comunicativo, ainda que limitado no caso de muitas espécies e, especialmente, naquelas anteriores à classe dos mamíferos na escala evolutiva. Um exemplo recorrente em Linguística é o do sistema comunicativo das abelhas, dado a partir de movimento, indicando existência de alimento e sua direção (PETTER, 2004; GROLLA; FIGUEIREDO SILVA, 2014).

Parece-nos que humanos possuem alguma capacidade de produção neural a qual é compartilhada por várias faculdades importantes e que estas existem apenas de forma muito rudimentar em outros animais. Um tal elemento processual é a habilidade para manusear eficientemente estruturas hierárquicas: no domínio da língua, ela é o elemento recursivo da sintaxe [...] (FEDOR et al., 2009, p. 15).

Apesar dos animais possuírem um sistema comunicativo, segundo Fedor, Ittzés e Szathmáry (2009), o sistema linguístico humano apresenta particularidades, as quais tornam a língua extremamente complexa.

Tendo em vista que o sistema comunicativo dos animais é eficaz entre as mesmas espécies, inviabilizando, neste caso, uma comunicação eficaz entre uma ave e um cachorro, assume-se com Reuland (2013) que os animais teriam algum aparato mental, que propicie o desenvolvimento de um sistema comunicativo, desenvolvido evolutivamente em algumas espécies de modo superior a outras. No caso do homo sapiens, teria havido uma provável virada radiológica (puramente ambiental), a qual motivou o desenvolvimento de uma mudança genética capaz de gerar o desenvolvimento da faculdade da linguagem, naturalmente. Por essa razão, apenas essa espécie do grupo hominídeo conseguiu produzir língua e sobreviver.

Fedor, Ittzés e Szathmáry (2009) argumentam que, no processo evolutivo da faculdade da linguagem, inicialmente, teria surgido o órgão em função de uma pré-disposição genética, acionada por algum evento de natureza ambiental, e que, dada esta mutação, a fisiologia da espécie também precisou evoluir para que a língua pudesse ser articulada. Deste modo, a língua teria sido produzida como produto do pensamento, a partir dos sistemas simbólicos e a comunicação seria posterior a esse sistema abstrato. A comunicação seria secundária no processo seletivo do homem em relação aos outros hominídeos. A capacidade de construir sistemas abstratos (=pensamento) parece ser muito mais relevante nesse processo, por exemplo, é mais relevante para o homo sapiens, em contexto de seleção natural, produzir fogo a partir de madeira e combustão do que discutir essa ou outras possibilidades já articuladas na mente, através do pensamento.

Os autores anteriormente mencionados, assim como Reuland (2013) e Berwick e Chomsky (2016), assumem que as mudanças genéticas, as quais afetam mais diretamente a linguagem, sejam provenientes de alguma variação no gene FOXP2. Esse gene foi descoberto numa mutação genética de uma família de falantes de inglês (GOPNIK, 1990, 1999). Os efeitos identificados foram dispraxia orofacial (disfunção motora neurológica que impede o cérebro de desempenhar movimentos corretamente) e dispraxia verbal ou apraxia da fala (comprometimento, no caso dos sujeitos observados, da morfologia e da sintaxe da língua). Entretanto, esse gene também foi encontrado em outras espécies, de modo que, atualmente, em biologia, interpreta-se que ele seja responsável pela interação (seja ela motora ou articulada). Por conta disso, Fedor, Ittzés e Szathmáry (2009) sugerem, com base em Greenfield (1991), que haja recursividade em outros domínios, tais como manipulação de objeto ou gramática de ação, por conseguinte, "[...] a capacidade de manusear recursividade aparece de diferentes formas de espécie para espécie” (FEDOR et al., 2009, p. 18).

O FOXP2, de fato, é um gene que foi descoberto em muitas espécies (HELLIARD; WHITE, 2009), mas apenas os humanos possuem língua. Provavelmente, a disposição do FOXP2 ao desenvolvimento de língua esteja relacionada a sua atuação paralela a outros genes específicos dos humanos. Aparentemente, o FOXP2 agrega funcionalidades acionadas na medida em que outros genes estão presentes no código genético da espécie em questão. É possível que, na medida em que a espécie avance na escala evolutiva, o gene acumule mais funções. O caso do homo sapiens ocasionou no surgimento da língua, mas em outras espécies promoveu mutações pertinentes à fisiologia dos mesmos. 


\subsection{A ARQUITETURA DA LINGUAGEM}

A configuração da arquitetura da linguagem é um saldo do empreendimento gerativista, cujo início deu-se na década de 1980, com a adoção do modelo ${ }^{2}$ de Princípios (regras rígidas, gerais e comuns a todas as línguas humanas) e Parâmetros (princípios variáveis acionados com base no input), e que acompanha a maioria das teorias do Programa Minimalista (PM). Apesar do PM não ser um novo quadro teórico da Teoria Gerativa, ele apresenta um novo olhar acerca da Faculdade da Linguagem visando atingir a adequação explicativa.

Considerando que o PM permite uma vasta gama de discussões de aspectos da mente e da cognição humana de maneira muito mais significativa do que os modelos Transformacional e de Regência e Ligação, a faculdade da linguagem passa a ser concebida como um órgão mental, cognitivo, responsável pela derivação de sentenças. A língua atuaria com base em uma relação contínua de sistemas de produção e sistemas de recepção,

[...] [t]anto os sistemas de pensamento quanto os sistemas de produção/compreensão são sistemas externos à linguagem, ou seja, não fazem parte dela ainda que façam um contato estreito. Na tradição do gerativismo temse chamado esses sistemas externos de sistemas de desempenho, também conhecidos como sistemas de performance (FERRARI-NETO, 2012, p. 35)

Para Hauser, Chomsky e Fitch (2002), a faculdade de mediação da comunicação humana parece notavelmente diferente da de outras criaturas vivas, isto leva a crer que "[...] a faculdade da linguagem humana parece ser organizada como um código genético hierárquico, gerativo, recursivo, e sem limites virtuais a respeito deste escopo de expressão" (HAUSER; CHOMSKY; FITCH, 2002, p. 1569). Neste trabalho, propõe-se que haja uma Faculdade da Linguagem em sentido amplo (FLB) e uma Faculdade da Linguagem no sentido estrito (FLN). A primeira inclui um sistema computacional interno, no qual FLN estaria contido, combinado com pelo menos dois sistemas orgânicos internos, o sensório-motor (ou articulatório-perceptual) e o conceitual-intencional. O segundo, por sua vez, é o único sistema linguístico computacional e abstrato, independente dos sistemas com os quais interage em interface, assim, FLB contém FLN.

\footnotetext{
Nós assumiremos, colocando de lado o mecanismo preciso, que uma componente chave de FLN é um sistema computacional (sintaxe estreita) que gera representações internas e as mapeia dentro da interface sensório motora, pelo sistema fonológico, e dentro de uma interface conceitual intencional, pelo sistema semântico (formal) (HAUSER; CHOMSKY; FITCH, 2002, p. 1571).
}

A FLN opera exclusivamente com recursividade, especialmente, no nível sintático, enquanto a FLB seria lida, incialmente, com as interfaces articulatório-perceptual e conceitual-intencional, mas também dialoga com módulos externos como social, cultural, psíquico e ecológico. Para os autores mencionados acima, a FLN seria exclusiva aos humanos, ao passo que a FLB estaria presente tanto em humanos, quanto nos outros animais. A questão que se coloca é se os sistemas comunicativos dos animais dispõem de recursividade, como os animais teriam apenas a FLB.

A recursividade seria uma premissa universal para as relações de modo geral e, uma vez que ela está presente em todos os níveis, pode-se afirmar que haja diferentes tipos de recursividade no sistema comunicativo dos animais (FEDOR et al., 2009). Sendo assim, é possível que exista outro nível de recursividade na FLB. No entanto, no que tange a recursividade humana,

[...] a Faculdade da Linguagem opera com um conjunto de operações recursivas sobre traços estocados no Léxico, gerando representações para cada nível de interface, C-I e A-P - é a chamada derivação, que ocorre respeitando restrições de processamento e de memória, o que está na base da noção de fase (FERRARI-NETO, 2012, p. 36).

${ }^{2}$ Essa discussão será retomada adiante. 
A FLN atua recursivamente a partir de operações (merge e move) realizadas com primitivos atômicos (traços) (cf. CARVALHO, 2012). No sistema computacional (GU), há um léxico, composto por traços selecionados para atuar na derivação em sistema de checagem (CHOMSKY, 1995 e posteriores) ou valoração (FRAMPTON; GUTMANN, 2000), após as verificações de traços de sonda e alvo, o nível spell-out encaminha a sentença simultaneamente para as interfaces conceitual-intencional e articulatórioperceptual.

\section{A EVOLUÇÃO DA NOÇÃO DE PARÂMETRO}

Dentro da perspectiva que busca analisar o que particulariza as línguas naturais humanas da linguagem de outros animais, surge, como visto anteriormente, a hipótese de que a recursividade seja a tal característica distintiva. Entretanto, também como visto acima, alguns autores problematizam essa visão, trazendo a ideia de que a recursividade também está presente nos sistemas cognitivos de outros animais, mas não de forma tão desenvolvida a ponto de gerar pensamentos complexos ou uma língua. No escopo dessas ideias, passou-se a analisar a noção de Princípios e Parâmetros como o que, de fato, permite a distinção das línguas humanas perante os demais sistemas de comunicação no reino animal. Dessa forma, na seguinte seção, investiga-se o caminho teórico que levou à criação da noção de Parâmetro, bem como as mudanças de aplicação do termo ao longo do desenvolvimento do gerativismo. Além disso, analisa-se as aplicações recentes do termo, dentro da perspectiva biolinguística.

A noção de parâmetro aparece na Teoria da Gramática a fim de resolver um problema antigo para toda teoria linguística: a variação sintática encontrada entre as línguas naturais e, mais recentemente, a variação encontrada dentro de uma mesma língua. Entretanto, para a linguística gerativa, essa preocupação começou mais tarde, uma vez que seu principal foco era explicar as regras mentais (os princípios) invariantes que regem o funcionamento das línguas naturais, em sua primeira versão, conhecido como modelo Padrão, do final da década de 1950 (CHOMSKY, 1957; 1965). A noção de parâmetro e, consequente, o problema da variação interlinguística só aparece no gerativismo, a partir da década de 1980, como o modelo de Regência e Ligação, também conhecido como modelo de Princípio e Parâmetros (CHOMSKY, 1981).

A ideia de parâmetro surge com intuito de resolver um problema lógico dentro da Teoria da Gramática Gerativa: o da aquisição da linguagem. Dentro do modelo Padrão, muitas eram as regras que definiam as transformações da estrutura profunda das línguas para a estrutura superficial. Essas eram regras de maior caráter descritivo, o que ia à contramão da teoria que visava um maior poder explicativo (CHOMSKY, 1986). Visando atingir esse objetivo, buscou-se pensar no que ficou conhecido como Problema Lógico da aquisição ou Problema de Platão, ou seja: como as crianças aprendem as regras de uma língua natural de forma célere e muito próxima para todas diante de um "input" imperfeito, sem que elas tenham algum conhecimento sobre o que sejam essas regras, ou ainda, do que seja uma língua? Esse problema guiou os autores a pensar em um modelo de gramática que desse conta da aquisição da linguagem. Para isso, a noção de Parâmetro foi fundamental, uma vez que explicou como as crianças conseguem aprender as diferentes línguas, mesmo de posse do mesmo conhecimento inato, já que esse é comum, por hipótese, a toda espécie humana.

Assim, o conhecimento que um falante adulto tem da sua língua, a sua competência linguística, é resultado da maturação de um estágio comum a toda espécie humana. Esse estágio comum, o $\mathrm{S}_{0}$, passou a ser conhecido como Gramática Universal (GU), em que estariam reunidos os Princípios, propriedades comuns a todas as línguas naturais, e os Parâmetros, propriedades variáveis das línguas naturais, que, em sua concepção, funcionam como características marcadas como presentes ou ausentes nas línguas. Dessa forma, é possível explicar o funcionamento da aquisição: o ser humano já nasce com algum conhecimento linguístico, simplesmente o que acontece é uma maturação deste conhecimento, que passa pela aprendizagem do léxico da língua-alvo e pela marcação dos Parâmetros que a regem a partir do input inicial ou, como também são chamados, a partir dos dados linguísticos primários.

Após a primeira noção de Parâmetro, apareceram na teoria muitos trabalhos comparando línguas, revendo dados das histórias das línguas, buscando observar a aquisição nas crianças. Com isso, a noção de Parâmetro evolui até chegar ao conceito que hoje temos na Biolinguística. No começo, os parâmetros estavam relacionados aos Princípios, como subespecificações, por exemplo, vinculavase o Parâmetro do Sujeito Nulo ao Princípio de Projeção Estendido, assim, entendia-se que todas as línguas possuem sujeito para os seus predicados; mas, em algumas, o sujeito é obrigatoriamente realizado foneticamente e, em outras, o sujeito fica nulo, ou seja, não

Carvalho, Cerqueira \& Mariano | Biolinguística: da evolução da espécie a noção de parametros 
realizado foneticamente, na forma de um pronome (pro). O problema com essa visão de Parâmetro está na verificação de que algumas línguas violam aquilo que vinha se entendendo com Parâmetro, como, no exemplo acima, é possível ver que existem línguas que variam entre deixar o sujeito nulo ou realizado, como o português brasileiro (PB).

Assim, a noção de parâmetro começa a ser revista dentro da Teoria da Gramática. De acordo com Kato (2002), os trabalhos de Wexler e Manzini (1987) e de Sportiche (1986) são os primeiros a buscar dissociar Princípios de Parâmetros, associando a noção de Parâmetros ao léxico. Entretanto, essa é uma visão que também não agrada, uma vez que, se os Parâmetros estão associados ao léxico, as línguas poderiam variar de forma infinita. Sabe-se que isso não condiz com a realidade, uma vez que as crianças levariam muito tempo para aprender uma língua natural se assim fosse. Acredita-se, portanto, que o número de Parâmetros é finito e reduzido, para que assim possa guiar o aprendizado rápido e eficiente da língua pelas crianças.

Dessa forma, para solucionar o problema descrito acima, passa-se a associar os Parâmetros somente ao léxico funcional, mais precisamente aos núcleos funcionais. Tal mudança acompanha a nova visão que se tem das estruturas sintáticas no modelo X-barra: ramificações binárias com núcleos funcionais c-comandando projeções lexicais, como os núcleos C, I e D. O primeiro trabalho a apresentar essa linha de raciocínio, de que os Parâmetros estão relacionados com a morfologia flexional, foi o de Borer (1984), sendo essa uma proposta cada vez mais assumida atualmente, principalmente dentro dos estudos de base gerativa em crioulística, remodelando antigas análises.

A partir do postulado de que os Parâmetros estão associados à morfologia dos núcleos funcionais (sendo que a presença ou não desses morfemas seriam responsáveis pela marcação ou não dos Parâmetros nas línguas, funcionando como um "gatilho" para a marcação paramétrica), buscou-se então definir em que nível da arquitetura das línguas os Parâmetros seriam aplicados. Tal busca pode ser exemplificada a partir da proposta que define que o Critério- $\mathrm{WH}$, que regula o movimento dos pronomes interrogativos para uma posição mais à esquerda na sentença, é um Princípio. Logo, todas as línguas deveriam ter o movimento dos pronomes interrogativos. Entretanto, não é isso que se observa.

Para resolver tal problema, propôs-se que esse movimento, quando não realizado foneticamente, acontecia no percurso entre o Spell-out e a Forma Lógica, não sendo lido, assim, pela Forma Fonética. Nesse sentindo, o movimento-WH aconteceria, em algumas línguas, no que se chamou de sintaxe encoberta, sendo parametrizado, então, o local, dentro da arquitetura em que o movimento ocorre. Além deste, há outros fenômenos que mostram que "[...] o que há de comum é que [...] a variação encontrada nas línguas envolve a fonologia [...]. Podemos, nesse sentido, dizer que a variação nas línguas se deve em grande parte à [sic] componentes fonológicos." (KATO, 2002, p. 324-325).

Outras propostas sobre Parâmetros passam a enxergá-los como conjunto de propriedades, assim:

Poderíamos dizer que tais estudos buscam não Parâmetros associados a Princípios, mas "princípios" associados a Parâmetros. Assim, uma propriedade singular de uma língua não constitui um Parâmetro, mas sim a manifestação substantiva de alguma propriedade formal abstrata da qual decorrem outras propriedades substantivas na língua. Esses "princípios" são similares aos universais de variação perseguidos desde Greenberg. (KATO, 2002, p. 325)

Destarte, é possível "subparametrizar" um Parâmetro. Essa é uma proposta que encontra guarida na análise do Parâmetro pro-drop, em que é possível categorizar as línguas quanto ao maior ou menor grau que o Parâmetro se revela. Assim, há línguas de sujeito nulo total, parcial (em alguns graus) e línguas em que não há sujeitos nulos.

Por fim, diante do debate feito, mostra-se que, de fato, ao que parece, os Parâmetros, ou seja, a variação linguística está associada ao léxico funcional das línguas, relacionados a: “a) de seus traços abstratos que levam ou não a deslocamentos de constituintes e b) da forma substantiva dos formativos gramaticais. O mistério do número de Parâmetros se resolve pela limitação das categorias funcionais e pela variação binária nelas encontrada” (KATO, 2002, p. 332). Deste modo, 
[a]pesar dos constantes questionamentos e reformulações na teoria como um todo e nas concepções sobre Parâmetro em particular, os ganhos empíricos da teoria a partir da introdução do conceito de Parâmetro são inquestionáveis. A sintaxe enveredou por pesquisas diacrônicas, por estudos comparativos e por projetos de aquisição, mostrando que, enquanto a arquitetura da gramática é invariante em seus aspectos abstratos, a diversidade morfo-fonológica, que faz o estofo da língua, apresenta uma incrível riqueza aparente, desvendada a cada dia pela teoria como uma função de um número limitado e previsível de Parâmetros (KATO, 2002, p. $333)$.

Dessa forma, ao chegar no Programa Minimalista (CHOMSKY, 1995), para o gerativismo, a variação paramétrica, bem como registrado anteriormente neste artigo, está ligada a propriedades mínimas das línguas naturais, conhecidas como traços, neste caso, os traços presentes nos núcleos funcionais, como os traços- $\varphi$ (phi) para os nomes ${ }^{3}$. São as relações entre estes traços, suas valorações (Princípio da Interpretação Plena (CHOMSKY, 1995)) e os movimentos que deles derivam, bem como a sua própria existência que vão levar ao conjunto de Parâmetros de uma determinada língua natural. Esse é o caminho da investigação sobre Parâmetros que se tem tomado dentro da teoria gerativa.

\subsection{PARÂMETROS E A BIOLINGUÍSTICA}

Uma análise biolinguística do fenômeno da variação deve começar, justamente, comparando as noções de variação para esses dois campos e identificar se eles se equivalem, ou seja, a pergunta a ser feita aqui é: a variação encontrada nas línguas reflete a variação encontrada na biologia? Caso a resposta seja afirmativa: seriam os Parâmetros uma propriedade mais geral da genética humana (ou animal), não se restringindo apenas à linguagem? Sendo a língua um produto da biologia humana, é esperado então que as variações biológicas sejam próximas à variação linguística, já que ambas têm as suas possibilidades determinadas geneticamente (no caso da língua, através dos Parâmetros), mas dependem da interação com fatores externos para se manifestarem (o que é 100\% válido para a língua, já que a marcação paramétrica se dá através dos dados linguísticos primários, mas não é válido para 100\% dos casos da variação biológica como um todo).

Di Sciullo (2011) busca resolver essas questões lançando mão da noção de assimetria, que seria justamente a ligação entre a variação linguística e a variação biológica. A assimetria é tida como uma relação binária em que para todo A, B pertence a uma lista X, se A é relacionado com B, então B não é relacionado com A. Assim, a assimetria é comum à língua e é característica de várias relações linguísticas, como a precedência, c-comando, dominância etc., inclusive merge, tanto o externo, quanto o interno (movimento). Para Di Sciullo, essas relações, como visto anteriormente, estão vinculadas à valoração de traços e à assimetria, devendo encontrar uma contraparte no mundo biológico.

De fato, sabe-se, como mostra Di Sciullo, que pesquisas recentes têm apontado para a assimetria como uma característica importante da variação biológica, sendo ela responsável por “como as células se movem e se dividem” (DI SCIULLO, 2011). Sendo assim, a autora passa a questionar se existiriam "Parâmetros biológicos", que possuiriam, como característica principal, a assimetria. Para ela, tal visão é possível, uma vez que variações, como a visão diurna de primatas em relação à visão noturna de alguns mamíferos, apresenta uma pequena mudança genética, do tipo binário, que acarreta outras alterações até chegar em todas as diferenças entre estes olhos. Deste modo, cabe considerar que é possível haver uma contraparte biológica da variação paramétrica, algo esperado dentro da biolinguística e que elas compartilham, entre si, relações de natureza assimétrica.

A partir da análise das possibilidades de variação linguística serem determinadas por fatores da FLN e da comparação ente a evolução das espécies (filogênese) e a evolução da língua (mudança), Di Sciullo (2011) argumenta em favor da relação entre a variação paramétrica linguística e biológica. Para a autora, entender como a variação se dá na biologia levará a um maior entendimento de como ela ocorre e é restrita na língua pelas propriedades da FLN. Para a autora, tanto na biologia quanto na língua, relações assimétricas (mais complexas) são derivadas de relações simétricas. Assim, na língua, a necessidade dos dados linguísticos

${ }^{3}$ Cf. Carvalho (2012) para uma discussão mais aprofundada sobre a natureza e o papel dos traços- $\varphi$ na computação. 
primários seriam as relações simétricas que engatilhariam as relações assimétricas da FLN, marcando os Parâmetros e dando espaço à variação, em termos muito parecidos com o que acontece biologicamente.

Em uma visão diferente da de Di Sciullo (2011), Smith e Law (2013) defendem que não é a recursividade o fator distintivo da linguagem humana em relação às linguagens de outros animais, mas a variação paramétrica. Para os autores, somente a variação paramétrica é unicamente humana. É importante frisar que, para os autores desse trabalho, a recursividade é uma característica única das línguas humanas. Pensa-se que o que tem aparecido como prova de que a recursividade é uma propriedade da comunicação para outros animais é, de fato, uma confusão em relação à noção de recursividade proposta por Chomsky (1995) e que está pautada em um conceito matemático (se x é um número natural, então x+1 também é um número natural). A discussão sobre recursividade como característica da linguagem humana não está no escopo deste trabalho, entretanto, é importante marcar a posição de seus autores.

Após uma discussão das hipóteses que regem seu trabalho e de refazerem o percurso do surgimento da noção de varia paramétrica dentro da teoria gerativa, Smith e Law fazem uma lista de critérios para definir o que são Parâmetros, a fim de distinguir a variação paramétrica da língua humana de outras variações que ocorrem na linguagem animal, mais especificamente as variações nos cantos dos pássaros. Assim, para os autores, a variação paramétrica é definida pelos seguintes critérios: (i) a variação paramétrica é conhecida antecipadamente, uma vez que está definida dentro da FLN; (ii) as variedades licenciadas pela escolha paramétrica devem ser representadas cognitivamente; (iii) a variação paramétrica é sistemática, uma vez que, quando definida, aplica-se sistematicamente; (iv) a parametrização é dependente do input, uma vez que a marcação se faz a partir da exposição aos dados linguísticos primários; (v) a variação paramétrica deve ser determinística; (vi) o efeito da variação paramétrica nas línguas é discreto, em termos de que é marcação binária; (vii) a variação paramétrica é exclusiva, em termos de que cada língua só pode ter uma marcação para determinado Parâmetro, não sendo possível a marcação de ambas possibilidades na mesma língua (SMITH; LAW, 2013).

Após definir esses critérios para o que é a variação paramétrica nas línguas humanas, Smith e Law passam a utilizá-los a fim de dizer se a variação encontrada no canto dos pássaros é paramétrica. De forma geral, os autores chegam à conclusão, com base nos critérios estabelecidos, de que a variação do canto dos pássaros não é paramétrica. Assim, eles mantêm a hipótese de que os Parâmetros são a característica distintiva das línguas humanas para a linguagem dos animais. É importante registrar que os próprios autores indicam que pesquisas posteriores possam mostrar o equívoco dessa reivindicação. Todavia, acredita-se que, para que haja parametrização, é necessário que haja GU. Logo, é de se esperar que somente os humanos tenham variação paramétrica, já que, por hipótese, a GU é exclusiva desta espécie.

Para fins de estudos em biolinguística, os trabalhos aqui trazidos mostram os questionamentos que se tem feito em relação à parametrização dentro da teoria gerativa. A noção de parâmetros, como mencionado anteriormente, é basilar para a teoria da gramática, uma vez que ele consegue resolver uma questão crucial: a aquisição da linguagem por parte das crianças mesmo diante da quantidade de possibilidades observadas na análise interlinguística. Assim, o trabalho de Di Siciullo (2011) mostra que a variação paramétrica, dentro de uma análise biolinguística, deve ser entendida em um contexto maior da biologia da espécie e do próprio reino animal. Nessa perspectiva, sendo a parametrização uma dotação biológica da espécie humana, é esperado encontrar correlatos dentro da própria fisiologia humana, e de outros animais. Já Smith e Law (2013) mostram que essas correlações podem estar em outras características animais, mas não na linguagem, uma vez que os autores defendem que a parametrização é exclusiva da linguagem humana e responsável por sua diferenciação em relação a outras linguagens animais. A grande contribuição de Smith e Law (2013) é a descrição detalhada de critérios para variação paramétrica, servindo de base para outros estudos e comparações, a fim de tecer a natureza precisa destes parâmetros. 


\section{CONSIDERAÇÕES FINAIS}

Nesse artigo, foi feita uma discussão da vertente da teoria da gramática conhecida como biolinguística. O texto traz o percurso que a proposta biolinguística percorreu até os dias atuais, desde o começo da proposta da Gramática Gerativa, e seus principais questionamentos, que norteiam a investigação das análises biolinguísticas, a saber: (i) O que é o conhecimento de uma língua natural e como é colocado em uso?; (ii) Como as línguas se desenvolvem nas crianças?; e (iii) Como a capacidade linguística evolui na espécie humana? (CHOMSKY, 2005).

Diante dessa retomada de como a visão biolinguística se desenvolve dentro dos estudos da Gramática Gerativa, o texto mostrou os objetivos específicos dessa área, a partir dos questionamentos acima listados. Destarte, mostrou-se o interesse destes estudos em explicar como a língua se desenvolveu no ser humano e quais as consequências que esse processo traz para o próprio funcionamento da linguagem. Seguindo esse raciocínio, buscou-se relacionar o processo de evolução da língua com a arquitetura que as línguas humanas assumem, sendo que esta é consequência daquela.

Toda essa discussão é feita dentro da perspectiva teórica do modelo de Princípios e Parâmetros, considerado fundamental dentro da teoria, uma vez que resolve a questão da aquisição e, portanto, abre interessantes questões para os estudos biolinguísticos. A fim de problematizar essas questões para a biolinguística, é feito aqui um percurso que a noção de Parâmetros seguiu dentro da teoria gerativa, até chegar ao ponto atual: de que Parâmetros são determinados e determinadores dos traços presentes nos núcleos do léxico funcional. Por fim, buscou-se estabelecer questões cruciais para o entendimento da noção de variação paramétrica dentro de uma perspectiva evolucionista da linguagem, a saber: (i) se a variação paramétrica encontra correlatos dentro da biologia da espécie humana ou do reino animal, uma vez que, já que se trata de uma dotação biológica, deve ser característica de outros elementos biológicos; (ii) se a variação paramétrica é exclusiva da linguagem da espécie humana, uma vez que, por ser uma propriedade da FLN, deve ser restrita à língua desses indivíduos, mas não exclui a verificação deste em outros aspectos biológicos; (iii) qual a natureza da variação paramétrica?

Assim, este artigo apresenta, para os leitores, novas investigações dentro do campo da Teoria da Gramática Gerativa e das ciências biológicas como um todo. Além disso, abre espaço para novas análises a partir da comparação da variação paramétrica das línguas da espécie humana e de outras variações, tanto das capacidades biológicas, quanto das variações observadas dentro de outras linguagens animais.

\section{REFERÊNCIAS}

BERWICK, R.; CHOMSKY, N. Why only us? Language and evolution. Cambridge: MIT Press, 2016.

BORER, H. Parameytric syntax. Dordrecht: Foris, 1984.

CARVALHO, D. S. Traços. In: FERRARI-NETO, J; SILVA, C.R.T (Org.). Minimalismo em foco: princípios e debates. 1.ed. Curitiba, PR: CRV, p. 113-132, 2012.

CHOMSKY, N. Syntactic structures. Mouton: The Hague, 1957.

Knowledge of language: its nature, origin, and use. New York: Praeger, 1986.

The minimalista program. Cambridge, Massachusetts: MIT Press, 1995.

. Three factors in language design. Linguistic Inquiry, v. 36, n. 1, winter, p. 1-22, 2005.

On minds and language. Biolinguistics. v.1, p. 1-22, 2007.

Carvalho, Cerqueira \& Mariano | Biolinguística: da evolução da espécie a noção de parametros 
CHOMSKY, N. The language capacity: architecture and evolution. Psychon Bull Rev, p. 1-4, 2016.

DI SCIULLO, A. M. A Biolinguistic Approach to Variation. In: DI SCIULLO, M. A.; BOECKX, C. The biolinguistic enterprise: News perspectives on the evolution and nature of the human language faculty. New York: Oxford University Press, 2011. 305-326.

; BOECKX, C. The biolinguistic enterprise: News perspectives on the evolution and nature of the human language faculty. New York: Oxford University Press, 2011.

FEDOR, A.; ITTZÉS, P.; SZATHMÁRY, E. The biological background of syntax evolution. In: BICKERTON, D.; SZATHMÁRY, E. (Ed.). Biological foundations and orgins of syntax. Cambridge Massachusetts: MIT Press, 2009. p. 15-39.

FERRARI-NETO, J. O minimalismo: conceitos-chave. In: FERRARI-NETO, J.; TAVARES, C. R. Programa minimalista em foco: princípios e debates. Curitiba: Editora CRV, 2012. p. 29-41.

FINGER, I. A aquisição da linguagem na perspectiva behaviorista. In: QUADROS, R. M; FINGER, I. Teorias de aquisição da linguagem. Florianópolis: Editora UFSC, 2008. p.17-44.

FRAMPTON, J.; GUTMANN, S. Agreement is feature sharing. Ms.: Northeastern University, 2000.

GALLIESTEL, C. Introduction. In: GALLIESTEL, C. (Ed.). Animal Communication. Cognition. (Special Issue), n. 37, p. 1-2, 1990.

GROLLA, E.; FIGUEIREDO SILVA, M. C. Para conhecer: aquisição da linguagem. São Paulo: Contexto, 2014.

HAUSER, M.; CHOMSKY, N.; FITCH, W. The faculty of language: what is it, what has it, and how did it evolve? Science, v. 22 Nov, vol. 298, Issue 5598, p. 1569-1579, 2002.

HILLIARD, A.; WHITE, S. Possible precursors of syntactic components in others species. In: BICKERTON, D.; SZATHMÁRY (Ed.). Biological foundations and origins of syntax. Cambridge, Massachusetts: MIT Press, 2009. p. 161-183.

KATO, M. A evolução da noção de parâmetro. D.E.L.T.A., v. 18, n. 2, p. 309-337, 2002.

JENKINS, L. The three design factors in evolution and variation. In: DI SCIULIO, A. M.; BOECKX, C. (Ed.). The biolinguistic enterprise: new perspectives on the evolution and nature of the human language faculty. Oxford: OUP, 2011. p. 169-204.

LENNEBERG, L. Biological foundations of language. New York: Wiley, 1967.

LONGOBARD, G; GUARDiAnO, C. The Biolinguistic Program and Historical Reconstruction. In: DI SCIULLO, M. A.; BOECKX, C. (Ed.). The biolinguistic enterprise: news perspectives on the evolution and nature of the human language faculty. New York: Oxford University Press, 2011. p. 266-301.

MALTHUS, T. An Essay on the principle of population. an essay on the principle of population as it affects the future improvement of society with remarks on the speculations of Mr. Godwin, M. Condorcet, and other writers. Printed for J. Johnson, in St. Paul's Church-Yard, 1798. 
PETTER, M. Linguagem, língua, linguística. In: FIORIN, J. (Org.). Introdução à linguística. São Paulo: Contexto, 2004. p. 11-25.

REULAND, E. Recursivity of language: what can birds tell us about it? In: BOLHUIS, J.; EVERAERT, M. Birdsongs, speech and language. Exploring the evolution of mind and brain. Cambridge: MIT Press, 2013. p. 209-228.

SKINNER, B.F. Verbal Behavior. New York: Appleton Century Crofts, 1957.

SMITH, N.; LAW, A. Parametric variation: Language and birdsong. In.: BOLHUIS, J.; EVERAERT, M. (Ed.). Birdsong, Speech and Language: Exploring the Evolution of Mind and Brain. Cambridge, MA: MIT Press, 2013. 125-141.

SPORTICHE, D. Jibun. Linguistic Inquiry, n.17, p. 369-374, 1986.

STEMMER, B. Pragmatics: theoretical and clinical issues. Brain Lang, v. 68, p. 389-391, 1999.

TATTERSALL, I. Becoming human: evolution and human uniqueness. New York: Harcourt Brace, 1998.

WEXLER, K; MANZINI, R. Parameters and learnability in binding theory. In: ROEPER, T.; WILLIAMS, E. (Ed.). Parameter setting. Dordrecht: D. Reidel, 1987. 41-76. 